\title{
AVALIAÇÃO DA EDUCAÇÃO SUPERIOR NO BRASIL E PORTUGAL HOMOGENEIZAÇÃO OU DIFERENCIAÇÃO?'
}

\author{
Antonio Alberto da Silva Monteiro de Freitas*
}

Recebido: 27 abr. 2011

Aprovado: 08 ago. 2011

*Doutor em Educação pela Universidade Federal da Bahia, Diretor da Faculdade Social da Bahia, Salvador, BA, Brasil. E-mail: a.albertofreitas@hotmail.com

Resumo: Sob o ponto de vista teórico há uma forte tensão entre duas tendências internacionais de avaliação: homogeneização e diferenciação, que parecem conter contradições entre si e que fazem parte dos sistemas de avaliação da Educação Superior adotados em diversos países. A compreensão da relação entre as duas tendências internacionais é muito importante, principalmente quando essa relação é analisada não só teoricamente, mas também na prática avaliativa de dois sistemas nacionais de avaliação da Educação Superior de dois países - Brasil e Portugal - que têm percorrido caminhos diferentes, mas que também têm afinidades e pontos em comum em relação a essa temática. O objetivo principal desta pesquisa é analisar e comparar os sistemas de avaliação da Educação Superior dos dois países, identificando possíveis pontos de confluência e de antagonismo, principalmente em relação às características de universalidade e especificidade das práticas avaliativas. Para fazer essa análise, optou-se pela pesquisa bibliográfica e técnica de recolha de dados empíricos de natureza qualitativa e de planejamento relativamente aberto e flexível, utilizando a entrevista semiestruturada. A população de respondentes foi construída por dezoito pessoas (nove do Brasil e nove de Portugal) e foi utilizada a metodologia de estudo de caso para estabelecer entre os dois sistemas de avaliação parâmetros de similaridades e diferenças, considerando as categorias de análise selecionadas para este fim. Os principais resultados da pesquisa revelam que a avaliação padronizada e estandardizada é que foi sendo gradualmente apontada como um instrumento importante para a implementação da agenda educacional dos dois países, em detrimento da valorização das diferenciações institucionais.

Palavras-chave: Educação superior. Avaliação da educação superior. Avaliação da educação superior no Brasil. Avaliação da educação superior em Portugal. Sistemas de avaliação português e brasileiro. Estudo comparativo.

\section{EVALUATION IN HIGHER EDCATION IN BRAZIL AND PORTUGAL HOMOGENIZATION OR DIFFERENTIATION?}

Abstract: From the theoretical point of view there is a strong tension between two international assessment trends, homogenization and differentiation, which form part of the evaluation systems of Higher Education adopted in several countries and seem to be contradictory. It is very important to understand the relations between the two models and the two international trends, especially when it comes to an analysis which is not only theoretical, but also based on the evaluation practices of national systems in two countries - Brazil and Portugal - that have taken different paths, though presenting similarities with respect to this topic. This research aims to analyze and compare the higher education evaluation systems in both countries and identify common and different aspects, especially concerning the characteristics of universality and specificity in the evaluation practices. In order to perform this analysis, a bibliographic study was conducted and qualitative information was collected under a relatively open, flexible planning approach, by means of semi-structured

1 Este artigo é parte do resultado da tese de doutorado intitulada "Avaliação da Educação Superior: Um estudo comparativo entre Brasil e Portugal”, orientada pelo Prof Dr. Robert Verhine/UFBA. 
interviews. Eighteen interviewees participated, nine from Brazil and nine from Portugal, a case study was carried out so patterns of similarities and differences could be identified, considering that categories of analysis selected. The main results indicate that standardized evaluation has become an important tool for the implementation of the educational agenda in both countries, to the detriment of appraisals of institutional differentiations.

Key words: Higher education. Evaluation in higher education.Evaluation in higher education in Brazil. Evaluation in higher education in Portugal.Portuguese and Brazilian evaluation systems. Comparative study.

\section{INTRODUÇÃO}

Os esforços tentativos de leitura e sistematização da realidade da Educação Superior, desenvolvidos ao longo das leituras preparatórias e inspiradoras deste trabalho, permitem assinalar algumas características globais do Ensino Superior que parecem fazer parte de um panorama predominante nesse campo, originando uma pressão social por uma avaliação mais sistemática das IES. Essas características são as seguintes:

- Verificou-se uma expansão significativa dos sistemas do Ensino Superior, pressionada pelas novas demandas sociais por oportunidades de ensino, que ampliou significativamente o quantitativo mundial de matrículas na Educação Superior. Entre 1980 e 2000, esse quantitativo foi quintuplicado (BRENNAN; SHAH, 2000);

- Tal expansão gerou dois outros movimentos. Por um lado, provocou aumento nos custos da Educação Superior pública, o que, por sua vez, criou pressões por maior transparência e responsabilização no uso dos recursos públicos voltados para esse nível de ensino. Por outro lado, a rápida expansão deu origem a uma diversificação do sistema, com consequentes demandas para mudanças no modelo universitário de ensino que vigorou até então ${ }^{2}$;

- A expansão das matrículas, as demandas por diversificação e o aumento dos custos levaram os Governos a concederem maior autonomia às IES, sob a premissa de que o poder decisório conferido às autoridades institucionais lhes permitiria:

- oferecer uma melhor resposta às demandas e pressões locais;

2 No Brasil, a decisão dos governos por não manterem um modelo único de universidade centrada na indissociabilidade entre o ensino, a pesquisa e a extensão, que é demasiado dispendioso aos cofres públicos, e a forte pressão exercida por uma demanda reprimida proveniente de famílias sem tradição universitária, as quais buscam a Educação Superior com o objetivo de melhorar a sua posição no mercado de trabalho, levaram a uma diversificação do sistema que ocorreu, primordialmente, pela ampliação do setor privado. Em Portugal, houve uma expansão de Educação Superior, principalmente no ensino politécnico público e privado, caracterizando, do mesmo modo, a transformação de um ensino de elite para um ensino de massas. 
- utilizar os recursos públicos de maneira mais racional e efetiva;

- buscar fontes alternativas de recursos, desse modo diminuindo a carga financeira governamental (VERHINE, 2008, p. 168);

- Entretanto, a autonomia concedida às autoridades institucionais requereu maior responsabilização das instituições, mas a expansão do sistema através da multiplicação de estabelecimentos de Ensino Superior e da diversificação de escolhas daí decorrentes, acarretou consequentes interrogações e um forte desequilíbrio do binômio qualidade-quantidade, no que diz respeito ao ensino ministrado e à investigação produzida;

- A necessidade crescente de profissionais e mão-de-obra com elevada preparação nas áreas de ciência e tecnologia, decorrente das exigências da globalização econômica, da competição em nível mundial e da internacionalização da Educação Superior, considerando também a rápida obsolescência do conhecimento, conduziu à importância de aumentar a taxa de participação no Ensino Superior e na formação avançada através de mais anos de estudo. Pesquisas recentes mostram taxas de retorno crescentes para a Educação Superior, considerando que o valor econômico na Educação tem crescido diante da necessidade de gerar inovação (RODRIGUEZ; DALMAN; SALMI, 2008) ${ }^{4}$.

O somatório desses fatores expansão e diversificação do sistema, aumento de custos, responsabilização no uso dos recursos, concessão de maior autonomia às IES e o acelerado processo de internacionalização das atividades políticas e educacionais vem configurando um cenário da Educação Superior cada vez mais plural e mais complexo. Com isso, torna-se mais fácil justificar, e até exigir, por parte dos órgãos públicos, a implantação de processos avaliativos em larga escala através da criação de sistemas da Educação Superior nos diversos países; esta exigência tem crescido muito nas últimas décadas, sob a égide do controle de qualidade, e como garantia de que as IES, tanto públicas quanto privadas, possam desempenhar o importante papel que lhes é atribuído pela sociedade.

3 Esta redução de investimentos públicos e o crescente afastamento do Estado relativamente a sua responsabilidade com o financiamento da Educação Superior têm ocorrido, considerando vários aspectos das universidades públicas que têm vínculos diretos com a questão do financiamento: altas taxas de evasão, excessiva soma de recursos destinados à residência estudantil, restaurantes, bolsas, subsídios, subutilização das instalações físicas, baixa relação aluno/professor, uso de tecnologias muito atrasadas, custos financeiros elevados e crescentes, entre outras (UNESCO, 1999). Este conjunto de aspectos e fragilidades das instituições públicas do Ensino Superior levou a uma diminuição no volume de recursos dos fundos públicos para as universidades, diversificação das instituições com a ampliação das instituições privadas e a procura de outras fontes alternativas de financiamento por parte das instituições. O objetivo foi o de expandir a oferta de vagas sem, no entanto, ampliar a participação da rede federal e, consequentemente, dos gastos da União (AFONSO, 2000; CATANI; OLIVEIRA; DOURADO, 2002; AMARAL, 2003).

4 A perspectiva econômica da Educação Superior tem sido também partilhada em diversos relatórios elaborados pela Comissão Europeia. O conselho de ministros enfatizou a importância de desenvolver todos os setores educacionais que são vitais para o futuro da Europa, em particular os de formação técnica e vocacional e os de Educação Superior (COMISSÃO DAS COMUNIDADES EUROPEIAS, 1993). 
É no decorrer dos anos 90 que a avaliação das IES, tanto privadas como públicas, irrompeu como um tema prioritário, tanto nos países desenvolvidos como nos países em desenvolvimento. Não há, portanto, como compreender as transformações da Educação Superior, nos últimos anos, sem levar em conta as práticas de avaliação.

São muitos os valores envolvidos na avaliação institucional e as interfaces entre eles, por isso entende-se ser a avaliação um fenômeno complexo, contraditório e multirreferencial, nunca linear; cumpre finalidades distintas e atende a interesses diversos. Ela é um campo de conflitos e de disputas, consequentemente, ultrapassa a dimensão técnica e circunscreve-se num campo socioeconômico-político e cultural mais amplo, porque produz sentidos, consolida valores, provoca mudanças.

A avaliação sempre fez parte da vida humana de um modo mais formal ou menos formal. As pessoas passam grande parte do seu tempo avaliando: avaliam-se constantemente a si mesmas, aos seus atos e suas atitudes; avaliam o comportamento das outras pessoas; avaliam a qualidade de qualquer acontecimento e de qualquer objeto; avaliam centenas de coisas por dia. Estas avaliações diárias, não importa o quão informal sejam, são esforços para avaliar a qualidade de alguma coisa (RODRIGUES, 1998).

A avaliação faz parte, portanto, de qualquer empreendimento humano e, de um modo geral, está ligada à palavra valoração. Ela é, aliás, por definição, uma atividade de valoração ou de atribuição de valores. Etimologicamente, avaliar significa atribuir valor a alguma coisa, dar a valia e, por isso, não é uma ação neutra. Sendo a não neutralidade um fato, interessa, na avaliação, o "compromisso com o questionamento, com a crítica, com a expressão do pensamento divergente e a explicitação no plano das teorias, da epistemologia e dos métodos de investigação" (BRASIL, 2006a, p. 10). Nesse sentido, a avaliação é concebida como uma atividade complexa, um processo sistemático de identificação de mérito e valor que envolve diferentes momentos e diversos agentes, mas sempre relacionada a um ato de julgamento.

De acordo com Nevo, as várias definições de avaliação podem ser estruturadas em três grandes grupos: a avaliação centrada em objetivos, a avaliação descritiva e a avaliação valorativa. $\mathrm{O}$ primeiro grupo, que se refere à avaliação por objetivos, é, frequentemente, definido como comparação e confronto entre objetivos previamente determinados e as performances ou resultados observados e alcançados, definição atribuível a Tyler (1977 apud NEVO, 1986).

O segundo grupo, segundo Nevo, engloba as definições descritivas e, portanto, não valorativas, ou seja, a avaliação é realizada para reunir informações 
que possibilitam um estudo diagnóstico de determinada realidade, com vista a uma posterior tomada de decisão, definição atribuível a Stufflebeam (1978 apud NEVO, 1986). Para este autor, a qualidade da informação ocupa lugar de destaque, nesta concepção, porque a avaliação consiste na procura de informações úteis e na sua comunicação àqueles que têm que tomar decisões sobre o ensino ou sobre as instituições. O que se destaca nesta concepção de avaliação é, precisamente, a projeção sobre o processo, os insumos e não apenas sobre o produto ou o resultado, onde os critérios de utilidade e relevância assumem papel preponderante.

O terceiro grupo, segundo Nevo (1986), é a da avaliação valorativa ou predicativa e os defensores dessa perspectiva de avaliação afirmam que a avaliação pressupõe um juízo de valor e isso significa apreciar o mérito ou valor de algo. Esta é uma definição atribuída a Scriven (1967 apud NEVO, 1986). O nome de Scriven veio, definitivamente, marcar também a história e o desenvolvimento da avaliação em educação. A avaliação educacional constitui, para Scriven, uma constatação ou apreciação do valor da dimensão educativa; é um processo através do qual se determina mérito e o valor das coisas.

Luckesi (1998) reúne elementos desses três grandes grupos e afirma que a avaliação é o julgamento de valor sobre manifestações relevantes da realidade, tendo em vista uma tomada de decisão. Já Afonso (2003) diz que a avaliação é um processo sistemático para coletar informações válidas, quantificadas ou não, sobre uma determinada realidade ou atividade, permitindo, assim, sua valoração e posterior tomada de decisão, objetivando sua melhoria ou aperfeiçoamento.

Há ainda uma perspectiva da avaliação que, de algum modo, está ligada ao aspecto valorativo que é a dimensão política e a dimensão ética da avaliação, também referenciada por diversos autores. Para House (1992, p. 52) a avaliação é "é uma atividade que é afetada por forças políticas e que tem efeitos políticos" ou "a avaliação não só deve ser veraz e crível, também deve ser ética e justa".

Além destas definições de avaliação de caráter mais amplo alguns autores discutem duas tendências internacionais de avaliação que assumem, neste trabalho, papel preponderante que são a homogeneização e a diferenciação de critérios avaliativos no contexto da internacionalização da Educação Superior (QIANG, 2003; KNIGHT, 2010).

A internacionalização da Educação Superior em diversos países é utilizada para alcançar metas institucionais e melhoria dos sistemas educativos, levando em conta sua realidade diversificada, mas, ao mesmo tempo, representa uma resposta da Educação Superior à globalização com tendência a uma padroniza- 
ção de critérios e de políticas (ROQUE NETO, 2010). Neste quadro, torna-se relevante desenvolver processos de acreditação que respondam à dimensão internacional, e que possam garantir o estabelecimento de critérios mínimos de qualidade a serem seguidos pelas IES. A acreditação de programas acadêmicos e o processo de reconhecimento ou validação de títulos universitários estão se tornando requerimentos indispensáveis de "Estratégias de Internacionalização das Universidades" (CHAPARRO, 2010).

Os sistemas de garantia e fomento da qualidade e acreditação estão desempenhando um papel estratégico em diversas regiões do mundo como parte de processos de integração em relação à Educação Superior. As propostas que têm sido feitas nos diversos países assumem papéis também distintos, mas não excludentes. Estudos internacionais estão sinalizando que a característica mais marcante dos sistemas de avaliação do Ensino Superior na América Latina e Europa é a existência de problemas semelhantes e adoção de critérios uniformes e padronizados de avaliação entre os países, fruto da globalização econômica e da internacionalização da Educação Superior (DURHAM, 1996; BRENNAN; SHAH, 2000; MOLLIS; MARGINSON, 2007; AMARAL, 2005), pelos quais esses sistemas tornam-se cada vez mais convergentes nas suas políticas e estruturas formais.

Outros estudos de outros autores estão sinalizando para outra direção e, apesar de existir uma tendência de convergência, há variações importantes nos sistemas de avaliação moldadas por diferenças histórico-culturais. Para eles, uma avaliação de qualidade constrói-se na consideração da valorização das especificidades e da diversidade das instituições traduzidas nas suas missões e vocações próprias, indicando que poderá estar existindo uma tendência de avaliação pluralista, plurirreferencial, dinâmica e contextualizada (CONTERA, 2002; ESTRELA; SIMÃO, 2003; DIAS SOBRINHO, 2004; FELIX, 2008).

O campo da avaliação universitária em diversos países do mundo está, segundo esses mesmos autores, estruturado pelo poder, tensões e conflitos entre as tendências de avaliação acima analisadas e é com base nessas reflexões em curso que este estudo ganha significado, visto que tem como objetivo comparar duas realidades de dois países em desenvolvimento, sendo um da América Latina, o Brasil, inserido no contexto do Mercado Comum do Sul (Mercosul), e o outro, Portugal, inserido no contexto da União Europeia (UE) e do Processo de Bolonha. A comparação a ser feita identifica e reflete sobre a possível relação existente entre as duas tendências internacionais vigentes na Educação Superior e que constituem eixo estruturante dos sistemas de avaliação dos dois países. 
Pretende-se investigar como esses dois países - Brasil e Portugal -, com cultura e história interligadas ${ }^{5}$, vêm formulando e implementando suas respectivas políticas avaliativas para a Educação Superior, quer na forma como parecem sofrer ante o impacto externo dos condicionantes de natureza global, quer na forma como parecem ser influenciados pela necessidade de um maior respeito aos contextos locais e à finalidade e missão institucionais.

A grande questão deste estudo pode ser configurada no problema a seguir explicitado.

\subsection{Problema}

Como se manifestam as duas tendências internacionais de avaliação - homogeneização e diferenciação - nos dois sistemas nacionais de avaliação da Educação Superior do Brasil e de Portugal em relação à implementação das modalidades de avaliação interna e externa?

Até que ponto há uma homogeneização nas políticas de avaliação nos sistemas avaliativos dos dois países?

Até que ponto há um respeito às especificidades das instituições (diferenciação) nos sistemas de avaliação desses dois países?

\subsection{Objetivo Geral}

Analisar e comparar os dois sistemas nacionais de avaliação da Educação Superior no Brasil e em Portugal buscando identificar graus de manifestação das tendências internacionais - diferenciação e homogeneização - em relação às modalidades de avaliação interna e externa adotadas nos dois países.

\subsection{Objetivos Específicos}

I. Elaborar um breve histórico da Avaliação da Educação Superior no Brasil e em Portugal, evidenciando aspectos de sua natureza e especificidades dos dois sistemas avaliativos;

II. Elaborar um quadro síntese e examinar as diferenças e semelhanças existentes entre os dois sistemas nacionais de avaliação do Ensino Superior do Brasil e de Portugal, numa perspectiva de educação comparada, considerando

5 Os dois países possuem um tratado de aliança e amizade por conta dessas afinidades históricas e culturais. Integrando o chamado mundo lusófono, constituído basicamente por Portugal e suas ex colônias, esses países se aproximam "por questões políticas e culturais, permitindo imaginar comunidades de sentido, emergentes da partilha de um mesmo espaço lingüístico" (NOVOA, 2000, p. 128). 
as dimensões e categorias de análise selecionadas (sistema Brasil/ Portugal; modalidade de avaliação interna e externa, homogeneização/ diferenciação);

III. Fazer reflexões sobre as duas tendências internacionais de avaliação: homogeneização e diferenciação contidas nos sistemas dos dois países.

\section{ORIENTAÇÕES METODOLÓGICAS}

Para o desenvolvimento deste trabalho e, de acordo com os objetivos da investigação e com as características do problema, foi feita a opção por uma abordagem qualitativa global, estudo de caso e metodologia comparativa para chamar a atenção para semelhanças e contrastes sugestivos entre os casos (COLLIER, 1993). A etapa de procedimentos de coleta e tratamento de informações integrou duas fases: a pesquisa bibliográfica documental e a técnica de recolha de dados de natureza qualitativa: a entrevista- semi-estruturada com especialistas. Esta escolha decorreu da necessidade de escuta dos sujeitos envolvidos diretamente com a avaliação da Educação Superior e do interesse em sua capacidade e seus conhecimentos no campo específico. Os entrevistados foram integrados ao estudo não como um caso único, mas representando um grupo específico de especialistas (MEUSER; NAGEL apud FLICK, 2004).

\subsection{População}

Foram realizadas 18 entrevistas ( 09 no Brasil e 09 em Portugal), entre 2008 e 2010, com especialistas na área da avaliação, assim como com representantes do Governo dos dois países e que participaram na concepção e implementação dos dois sistemas nacionais de avaliação dos dois países.

\subsection{Categorias de Análise}

Foram consideradas três dimensões de análise, cada uma composta por duas categorias antagônicas.

Para cada bloco de categorias de análise foram identificados indicadores considerados no processo analítico, de maneira a permitir uma compreensão do conjunto de análise que se pretendeu desenvolver e suas inter-relações:

Dimensão 1: Sistema Brasil x Portugal.

Dimensão 2: Modelo de avaliação interna e externa.

Dimensão 3: Tendências internacionais: homogeneização e diferenciação. 
A análise da dimensão 1 focalizou duas categorias: "Sistema de Avaliação do Brasil" e "Sistema de Avaliação de Portugal" e alguns elementos constitutivos dos dois sistemas de avaliação dos dois países: ensino superior público e privado, instituições, cursos, atores e órgãos representativos dos dois sistemas.

A dimensão 2 focalizou e aprofundou a avaliação interna e avaliação externa e incidiu sobre os indicadores: finalidades, instrumentos e uso dos resultados dessas duas modalidades avaliativas.

A terceira dimensão está intimamente ligada com o problema de pesquisa, focalizou as duas categorias homogeneização e diferenciação presentes nos dois sistemas de avaliação e incide sobre a internacionalização da educação superior, valores locais x valores globais e a questão da avaliação x autonomia.

O Quadro 1 dá um panorama completo das dimensões, categorias e indicadores que nortearam o trabalho empírico e constituíram referencial básico para a análise comparativa.

\section{Quadro 1 - Dimensões, categorias de análise e indicadores, segundo avaliação Brasil x Portugal}

\begin{tabular}{|l|l|l|}
\hline Dimensões & Categorias & Indicadores \\
\hline Dimensão 1 & Sistema Brasil/ Portugal & $\begin{array}{l}\bullet \text { Ensino público e privado } \\
\bullet \text { Instituições/ cursos } \\
\bullet \text { Atores e órgãos representativos }\end{array}$ \\
\hline Dimensão 2 & Avaliação interna e externa & $\begin{array}{l}\bullet \text { Finalidades } \\
\bullet \text { Instrumentos } \\
\bullet \text { Uso dos resultados }\end{array}$ \\
\hline Dimensão 3 & $\begin{array}{l}\text { Tendências internacionais: ho- } \\
\text { mogeneizaçãox diferenciação }\end{array}$ & $\begin{array}{l}\bullet \text { Internacionalização da Educação Superior; } \\
\bullet \text { A avaliação e autonomia das IES; } \\
\bullet \text { Papel dos Governos e papel das instituições }\end{array}$ \\
\hline
\end{tabular}

Fonte: Quadro elaborado pelo autor.

\section{PRINCIPAIS RESULTADOS}

Apresenta-se, a seguir, o quadro síntese comparativo das principais características dos dois sistemas de avaliação do ensino superior (Brasil/ Portugal), pontos que aproximam os dois sistemas de avaliação e aqueles que são antagônicos. Procurou-se fazer uma correlação de cada categoria de análise de "per si" examinando pontos comuns e pontos que se diferenciam, mas seguindo um ordenamento e uma seqüência lógica e integrada entre os elementos. 


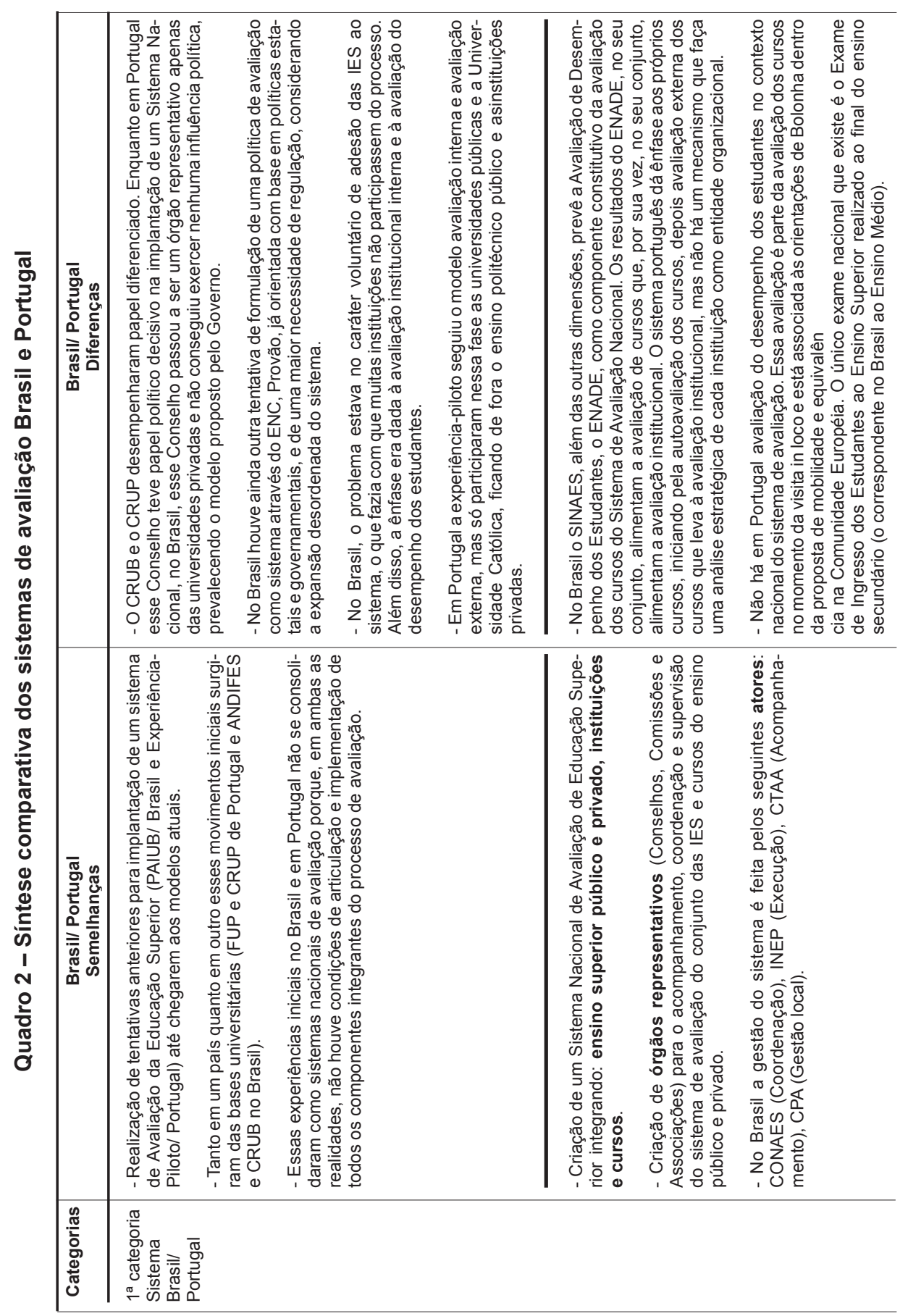




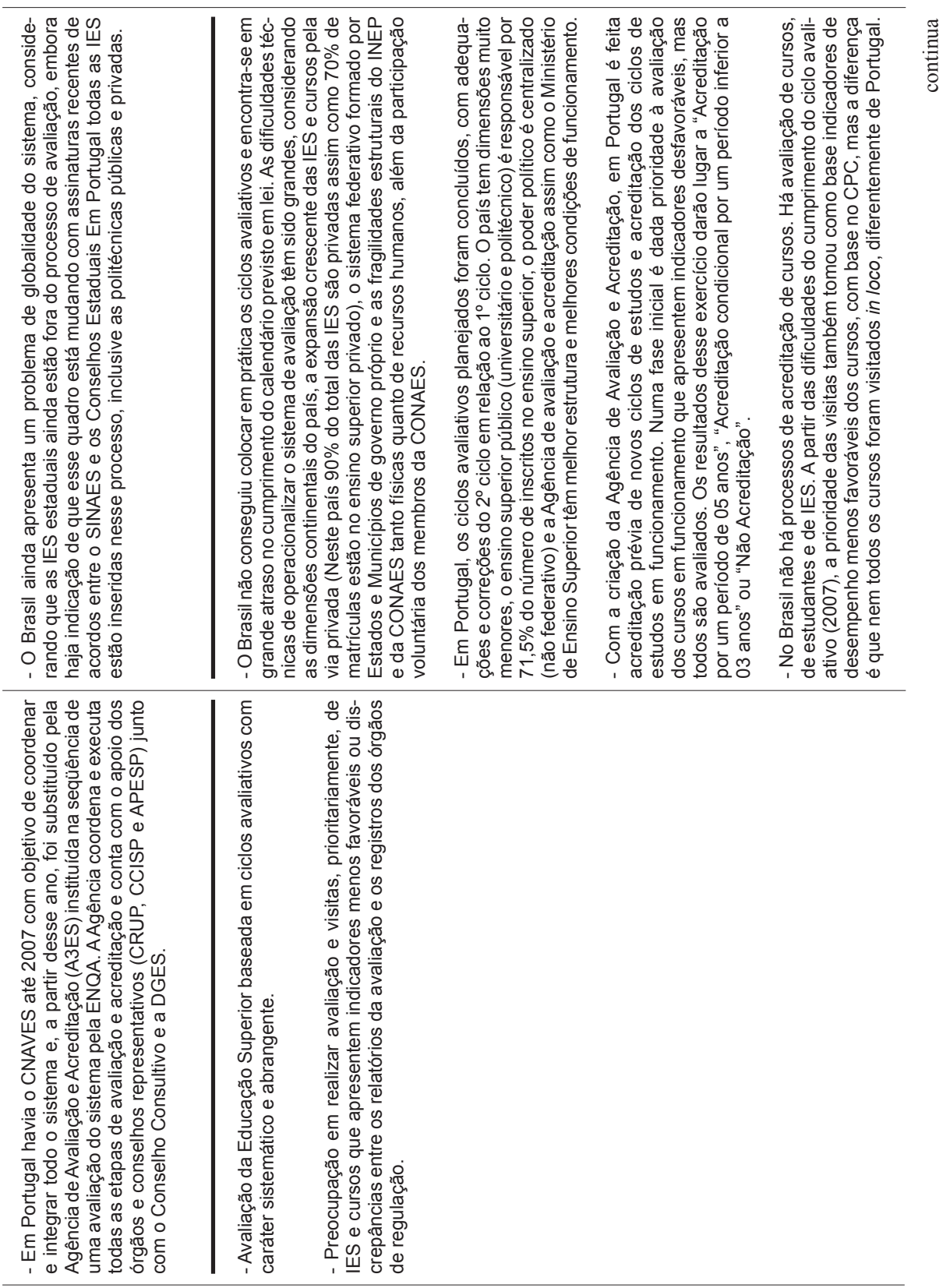




\begin{tabular}{|c|c|c|c|c|c|c|c|c|}
\hline 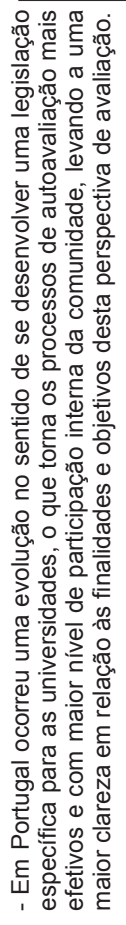 & 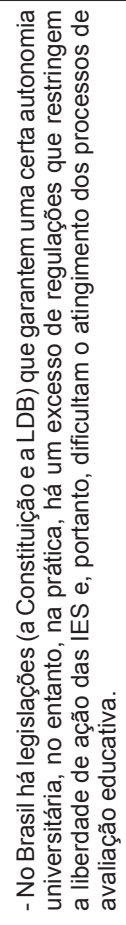 & 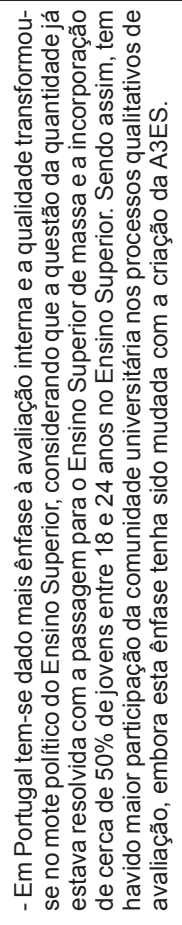 & 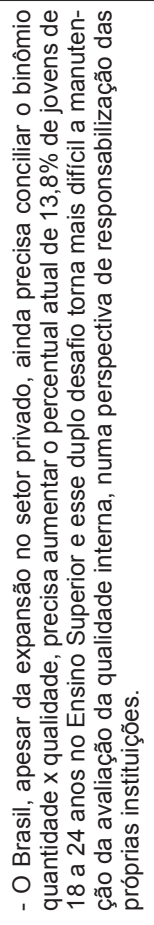 & 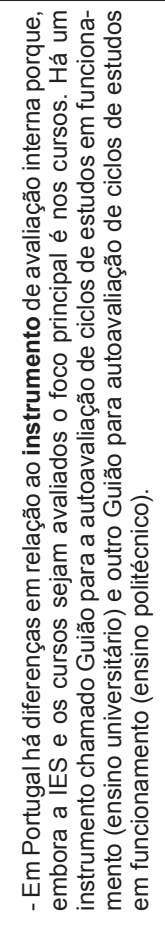 & 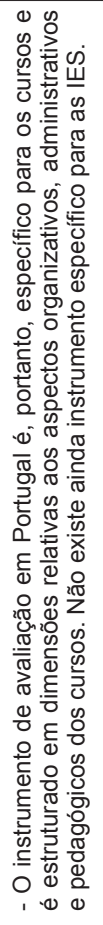 & 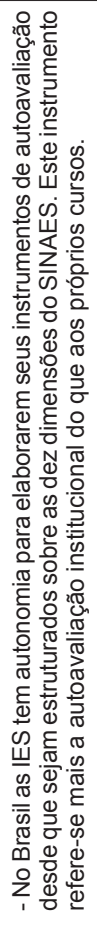 & 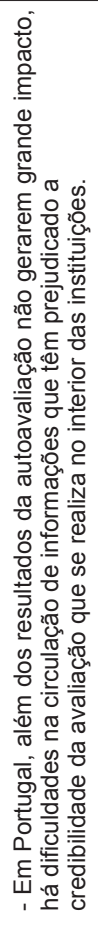 & 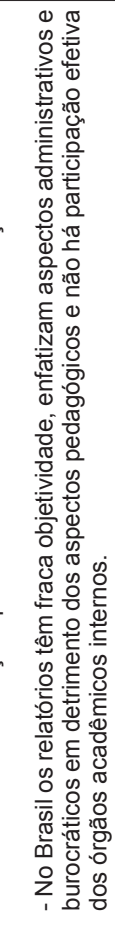 \\
\hline
\end{tabular}
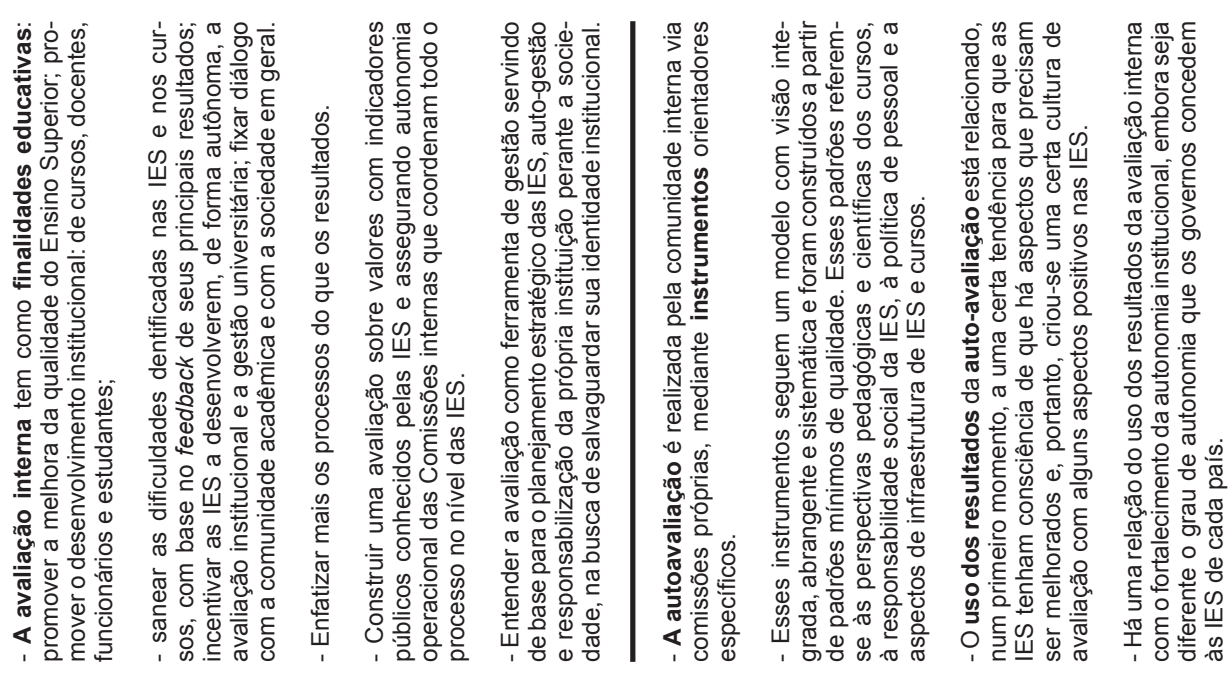

징 $\stackrel{0}{0}, 0$

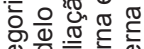

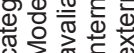




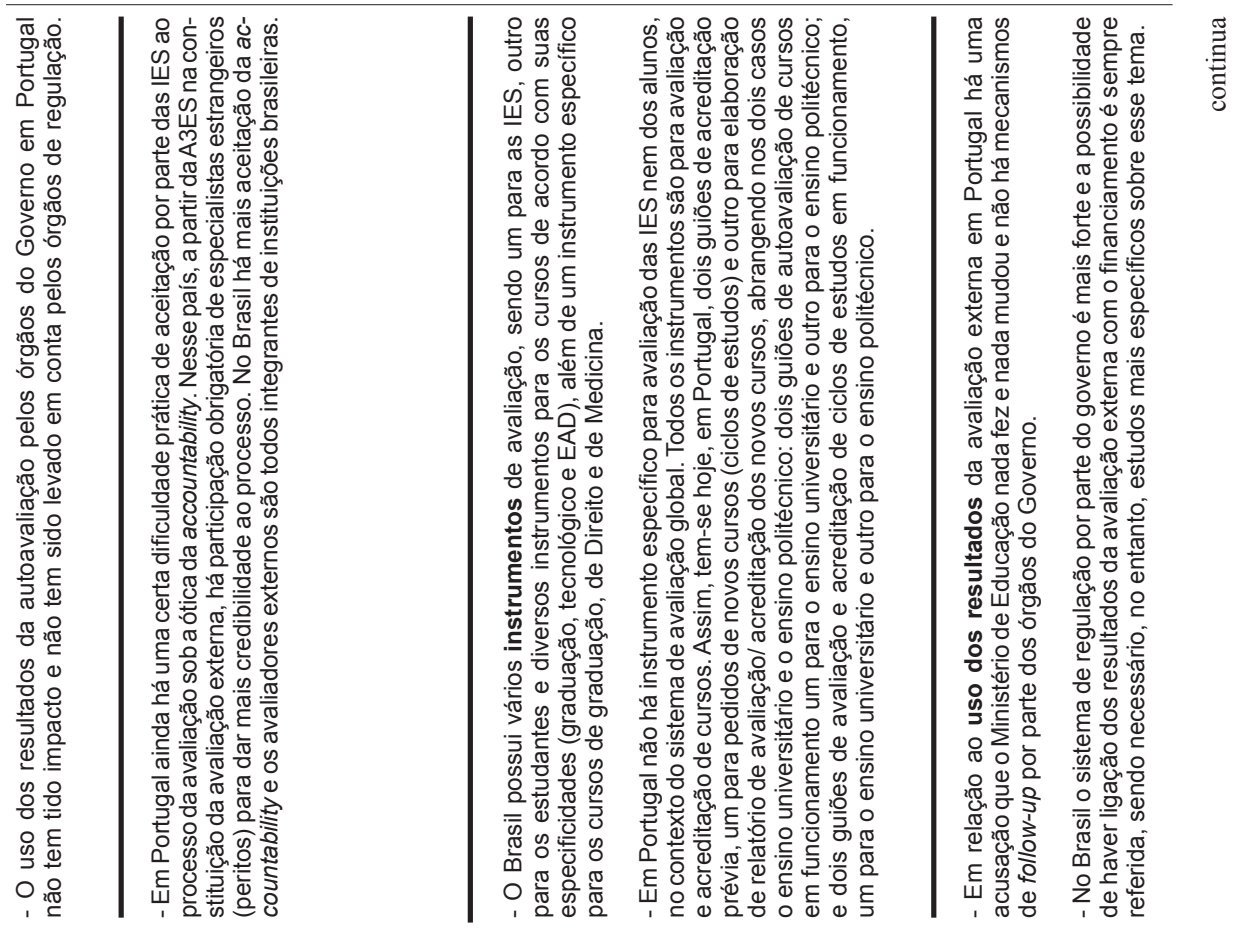

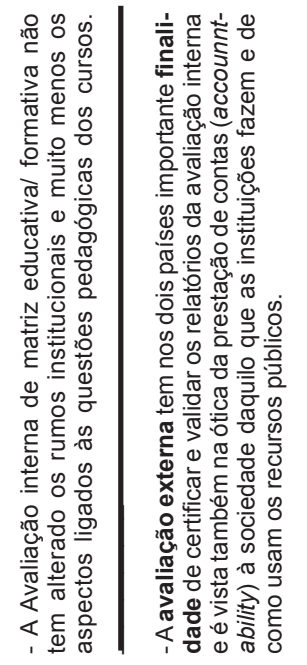

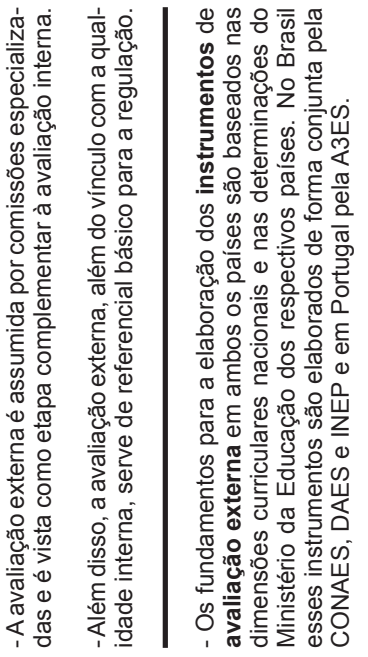

ํำ

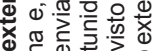

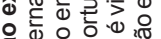

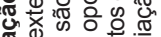

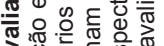

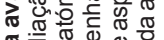
\% 에

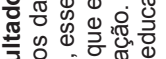

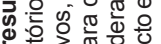

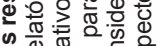

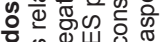

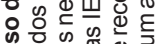
옥응 क

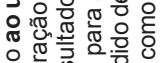

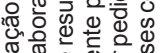

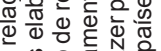

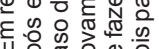




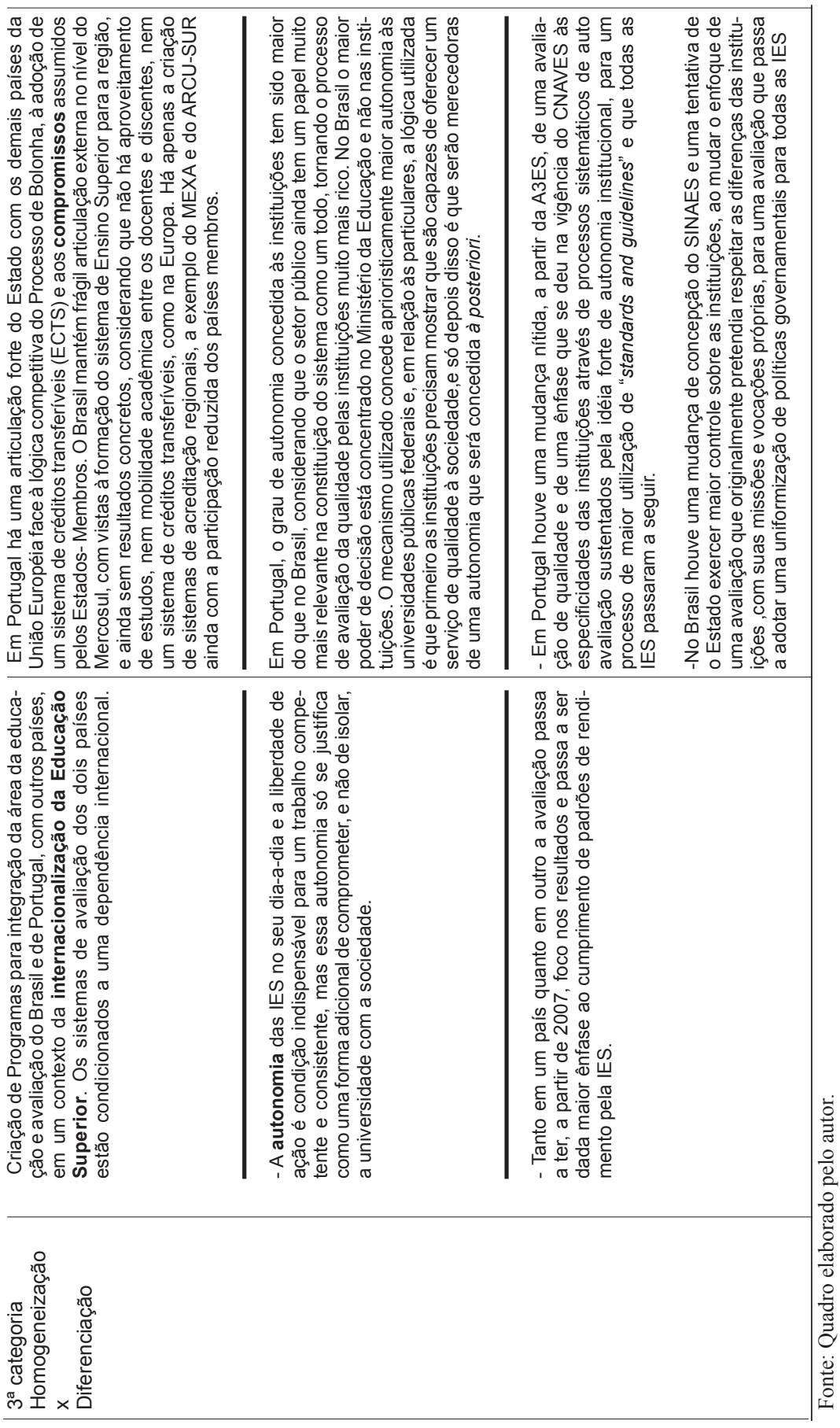




\section{CONCLUSÃO}

As experiências de avaliação seguindo critérios padronizados e homogêneos têm sido uma tendência mundial nos sistemas nacionais de avaliação de distintos países e organizações internacionais de avaliação de que são exemplos Brasil e Portugal.

Uma primeira reflexão que se pode fazer neste contexto é que, tanto em um país quanto em outro, a avaliação entendida como sistema não é uma atividade voluntária e sim uma política de Estado que estabelece etapas e cada uma dessas etapas contém standards ou padrões mínimos de referência e que todas as instituições e todos os cursos devem seguir.

Esses padrões de rendimento estão explicitados nos instrumentos de avaliação interna e externa de cada país e a expectativa é que haja o cumprimento de cada um deles, por parte das IES, assegurando dessa forma maior produtividade e melhores resultados. Nesse sentido, há o predomínio de uma orientação gerencialista (no Brasil) e managerialista (em Portugal) ${ }^{6}$ no sentido defendido pelo new public management que transpõe instrumentos e práticas de gestão típicas das organizações empresariais para as organizações públicas e que, no caso das universidades, estão cada vez mais presentes nos papéis dos pesquisadores, podendo entrar em contradição com a lógica do trabalho acadêmico tradicional. O corolário dessa orientação é a uniformização de estilos e práticas de gestão tanto nas universidades púbicas quanto nas privadas. Isso tem repercussões diretas nos processos de avaliação que seguem a mesma linha de eficiência, do foco em resultados e do cumprimento de padrões homogêneos estabelecidos pelos órgãos governamentais.

Esse controle pelo Estado através da padronização de critérios avaliativos é uma resposta à globalização e internacionalização da educação e a avaliação de Ensino Superior e não pode ser compreendida em cada país, longe das macro políticas que lhe dão sustentação. Ao contrário do que inicialmente se previa a avaliação padronizada ou estandardizada (baseada em standards), isto é a avaliação que visa o controle de objetivos previamente definidos (quer enquanto produtos, quer enquanto resultados educacionais) é que foi sendo gradualmente apontada como um dos traços distintivos das mudanças nas políticas avaliativas dos dois países. Assim, a avaliação padronizada tornou-se um instrumento por excelência para a implementação da agenda educacional dos dois países e há um predomínio claro das forças homogeneizadoras em função das pressões

6 Em Portugal fala-se managerialismo em vez de gerencialismo para sublinhar, com o anglicismo, o caráter artificial da importação do modelo de gestão e administração das empresas para as universidades (Antônio Magalhães - CIPES/Portugal). 
externas e que demonstram ter desenvolvido influência direta na continuidade e no desenvolvimento nos sistemas avaliativos dos dois países.

\section{REFERÊNCIAS}

AFONSO, Almerindo Janela. Avaliação educacional: regulação e emancipação. São Paulo: Cortez, 2000.

. Estado, globalização e políticas educacionais: elementos para uma agenda de investigação. Revista Brasileira de Educação, Rio de Janeiro, n. 22, jan./fev./mar./abr. 2003.

AMARAL, Alberto. Bolonha, o ensino superior e a competitividade econômica. In: SERRALHEIRO, Jose P. O processo de Bolonha e a formação dos educadores e professores portugueses. Porto: Profedições, 2005.

AMARAL, Nelson Cardoso. Financiamento da educação superior estado x mercado. São Paulo: Cortez/Ed. UNIMEP, 2003.

BRASIL.MEC. Avaliação da educação superior: Diretrizes e instrumentos. Brasília, 2006a.

BRENNAN, John; SHAH, Tarla. Quality assessment and institutional change: experiencies from 14 countries. : London: Centre for higher Education Research and Information, Open University, 2000. p. 331-349.

CATANI; OLIVEIRA; DOURADO. A política de avaliação da educação superior no Brasil em questão. In: DIAS SOBRINHO; RISTOFF (Org.). Avaliação democrática para uma universidade cidadã. Florianópolis: Insular, 2002.

CHAPARRO. Fernando O. Acreditação, reconhecimento de títulos e mobilidade como instrumentos de integração. Boletim IESALC Informa de Ensino Superior, fev. 2010. Disponível em: <http://www.iesalc. unesco.org.ve/index.php?option $=$ com_content\&view $=$ article\&id $=1713$ :a creditacion-reconocimiento-de-titulos-y-movilidad-como-instrumentosdeintegracion\&catid=126:noticias-pagina-nueva\&Itemid=712\&lang=br $>$. Acesso em: 13 out. 2010. 
COLLIER, David. The comparative method. In: FINIFTER, Ada W. (Org.). Political science: the state of discipline II. Washington: American Political Science Association, 1993. p. 105-119.

COMISSÃO DAS COMUNIDADES EUROPEIAS. Os desafios e as pistas para entrar no século XXI. Bruxelas: Comissão das comunidades Europeias, 1993.

CONTERA, Cristina. Modelos de avaliação da educação superior. In: DIAS SOBRINHO; RISTOFF (Org.). Avaliação democrática. Florianópolis: Insular, 2002.

DIAS SOBRINHO, José. Avaliação ética e política em função da educação como direito público ou como mercadoria. Revista Educação e Sociedade, Campinas, v. 25, n. 88, 2004.

DURHAM, Eunice Ribeiro. Los studios comparativos de la educatión superior - variaciones sobre um mesmo tema em América Latina. In: KENT, Rollin (Comp.). Los temas críticos de la educatión superior em America Latina. Estudios comparativos. 1. ed.. México: Fondo de Cultura Económica, 1996.

ESTRELA, Maria Teresa; SIMÃO, Ana M. Veiga. Algumas reflexões sobre práticas de avaliação do ensino universitário e dos docentes a partir de informação recolhida no projeto Evaluation and self Evaluation of Universities in Europe (EVALUE). Revista Portuguesa de Avaliação, Braga, v. 16, n. 1, 2003.

FELIX, Glades Tereza. Reconfiguração dos modelos de universidade pelos formatos de avaliação: efeitos no Brasil e Portugal. 2008. Tese (Doutorado em Educação) - Programa de Pós-Graduação em Educação. Universidade Federal do Rio Grande do Sul, Porto Alegre, 2008.

FLICK, U. Uma introdução à pesquisa qualitativa. Porto Alegre: Bookman, 2004.

HOUSE, Ernest R. Tendencias en evaluación. Revista de Educación, Madri, n. 299, 1992.

KNIGHT, J. Updating the Definition of Internalisation. International Higher Education, Boston, n. 33, 2003. Disponível em: <www.bc.edu/ bcorg/avp/soe/cihe/news33/texto01.htm>. Acesso em: 01 mar. 2010. 
LUCKESI, Cipriano Carlos. Avaliação do aprendizado escolar: estudos e proposições. 8 ed. São Paulo: Cortez, 1998.

MOLLIS, Marcela; MARGINSON, Armon. The assessment of universities in Argentina and Austrália: between autonomy and heteronomy higher education. p. 311-330, 2002. Disponível em: <www.capes.gov.br $>$. Acesso em: jan. 2007.

NEVO, David. The conceptualization of educational evaluation: an analytical review of the literature. In: HOUSE, Ernest R. (Ed.). New directions in educational evaluation. Philadelphia, USA: The Falmer Press, 1986.

NOVOA, Antônio. A difusão mundial da escola. Lisboa: Educação, 2000.

QIANG, Zha. Internationalization of higer education: towards a conceptual framework. Policy Futures in Education, Toronto, v. 1, n. 3, 2003.

RODRIGUES, P. Avaliação da formação pelos participantes em entrevista de investigação. Tese (Doutorado em Ciências e Educação) FRCE de UL, Lisboa, 1998. Lisboa: FRCE de UL, 1998.

RODRIGUEZ, Alberto; DALMAN, Carl; SALMI, Jamil. Conhecimento e inovação para a competitividade. Trad.: Confederação Nacional da Indústria. Brasília: CNI, Banco Mundial, 2008.

ROQUE NETO, Carnot Jacy. Elementos de Internacionalização da Educação Superior na experiência ARCU_SUR_Arquitetura, 2010. Monografia (Conclusão de curso) - Universidade Federal de Integração Latino-Americana, Paraná, 2010.

UNESCO. Política de mudança e desenvolvimento no ensino superior. Trad. e ver. Laura Ferrantini Fusaro. Rio de Janeiro: Garamond, 1999.

VERHINE, Robert Evan. Avaliação da CAPES: subsídios para a reformulação do modelo. In: MACHADO, D; SILVA JR; OLIVEIRA, J. F. (Org.). Reforma e políticas: educação superior e pós-graduação no Brasil. Campinas: Alínea, 2008. p.165-188. 